\title{
Fast-track extubation in patients after intracranial hematoma surgery
}

\author{
GUSTAVO GONZÁLEZ-CORDERO ${ }^{1}$, BELIA INÉS GARDUÑO-CHÁVEZ ${ }^{1}$, DIONISIO PALACIOS-RÍOS ${ }^{1}$, \\ YESENIA NOHEMÍ ESTRADA-SOLÍS ${ }^{1}$, IRAM PABLO RODRÍGUEZ-SÁNCHEZ ${ }^{2}$ \\ and ÁNGEL RAYMUNDO MARTÍNEZ-PONCE-DE-LEÓN ${ }^{3}$
}

\author{
${ }^{1}$ Servicio de Anestesiología, Universidad Autónoma de Nuevo León, Facultad de Medicina y Hospital Universitario ‘Dr \\ Jose Eleuterio Gonzalez, Monterrey, Nuevo León 64460; ${ }^{2}$ Laboratorio de Fisiología Molecular y Estructural, Universidad \\ Autónoma de Nuevo León, Facultad de Ciencias Biológicas, San Nicolás de los Garza, Nuevo León 66450; \\ ${ }^{3}$ Servicio de Neurocirugía, Universidad Autónoma de Nuevo León, Facultad de Medicina y Hospital \\ Universitario ‘Dr Jose Eleuterio Gonzalez', Monterrey, Nuevo León 64460, Mexico
}

Received December 19, 2017; Accepted March 7, 2019

DOI: $10.3892 /$ etm.2020.8507

\begin{abstract}
Early extubation, also known as fast track, is desirable after intracranial hematoma surgery to avoid ventilator-associated complications associated with admission to an intensive care unit (ICU). The objective of the present study was to determine whether ICU stay and ventilator-associated complications are reduced in patients who received surgery for intracranial hematoma if they are extubated early. A total of 17 patients were randomly assigned to two groups: In Group 1, patients were extubated early or using the fast track method, while those in Group 2 were conventionally extubated at a later stage and were managed at the ICU. Patients from both groups were assessed on admission to the operating room per the established standards and after the selection criteria had been confirmed, general anesthesia was applied. Extubation time and hemodynamic stability (number of anesthetic adjustments required to maintain hemodynamic parameters within $20 \%$ of the predicted values) were assessed post-operatively. Patients in the conventional group $(n=10)$ were transferred to the ICU and extubated at $8 \mathrm{~h}$ post-operatively; hemodynamic stability and the presence of complications were evaluated. The fast track group had no complications associated with ventilation or any other parameter. All patients extubated in a conventional manner and who were transferred to the ICU presented with complications, including seizures, aspiration, atelectasis or failed extubation. In the future, fast track should
\end{abstract}

Correspondence to: Dr Gustavo González-Cordero, Servicio de Anestesiología, Universidad Autónoma de Nuevo León, Facultad de Medicina y Hospital Universitario 'Dr Jose Eleuterio Gonzalez', Av. Francisco I. Madero y Gonzalitos S/N, Monterrey, Nuevo León 64460, Mexico

E-mail: ggcordero@yahoo.com

Key words: fast track, intracranial hematoma, post-surgery patients, intensive care unit, avoidance of complications be regarded as a routine technique in patients who meet the required criteria, so that they may be discharged quickly and with fewer complications. The present study was authorized by the ethics committee of the hospital and the research sub-directorate with the number AN14-003; it was submitted to and approved by the ISRCTN registry for clinical trials (ID, ISRCTN16924441).

\section{Introduction}

Early extubation or fast track techniques are used in areas as diverse as routine cardioanesthesia and post-surgical anesthesia, and they are also used during neuroanesthesia $(1,2)$. An even greater effect occurs in anesthesiology, mainly as the assessment of a patient's neurological condition in a conscious individual is the best and least expensive neuromonitoring method available (3). Early extubation should be performed jointly with neurosurgery so that execution of the technique does not negatively alter the result of surgical procedure. In the present study, the role of early extubation in neuroanesthesia was evaluated, considering the physiopathological repercussions and the benefits and drawbacks of early and late awakening, providing a basis for the establishment of a possible rapid transitional anesthetic plan. Early awakening and extubation in neuroanesthesia are desirable and possible in numerous cases.

It is estimated that $\sim 200,000$ patients per year require mechanical ventilation due to neurological damage in the USA (1). The neurosurgical patient poses a series of challenges to the clinician with regard to airway management, mechanical ventilation and determination of the ideal time-point for extubation. Prior neurological damage may, directly or indirectly, influence control of breathing or the airways. For this reason, extubation criteria should be reviewed for each patient.

The rate of mortality of neurosurgical patients who require airway control and ventilatory assistance ranges between 20 and $50 \%$. The cost associated with the care of these patients has been estimated at $>25$ billion dollars per year in the USA. 
Therefore, decreasing the time on mechanical ventilation has a great medical and economic significance (2). Extubation of the neurosurgical patient requires particular consideration of respiratory mechanics and airway resistance, as well as specific factors relevant to the neurosurgical patient in terms of endotracheal tube withdrawal and avoidance of the use of mechanical ventilation as much as possible (3).

Fast track is an alternative in neurosurgical patients that avoids, as much as possible, the use of mechanical ventilation in the intensive care unit (ICU) and the associated complications. It is based on the premise that assessment of the neurological condition in a conscious patient is the best and least costly neuromonitoring method available (4). A patient who wakes up from anesthesia in the operating room and is then transferred to the recovery room and then to the ward has a lower risk of acquiring a nosocomial infection, atelectasis, pneumonia, ventilator complications and other risks inherent in the ICU. Reducing or avoiding stays in the ICU allows for an increase in survival and reduces the risk of illness for the patient in addition to reducing costs for both the patient and the institution.

Early recognition of central nervous system dysfunction reduces complications. In the neurosurgical patient, complete recovery of consciousness is the most important issue for the surgical team. Intracranial surgery is rarely performed on a normal brain; therefore, post-surgical assessment may pose a certain degree of difficulty. Invasion of the airways should be discontinued as soon as practically possible. Extubation is a critical procedure and constitutes a determinant of the immediate future of the surgical patient in terms of satisfactory recovery or life-threatening complications (5). Since the beginning of the 21st century, attempts have been made to create early extubation protocols in neuroanesthesia. However, there is no consensus as to when and in what patients early extubation should be attempted (6). An adequate anesthetic technique that allows for rapid awakening of a neurosurgical patient is not exempt from possible complications. Certain systemic and neurological situations must always be considered, since mismanagement of these aspects may complicate a rapid extubation technique $(7,8)$.

At present, evaluation of the neurological condition in a conscious patient is the best and least expensive neuromonitoring method; therefore, early awakening of these patients represents a trend that is on the rise. For this reason, the objective of the present study was to determine whether less ventilator-associated post-surgical complications occur when patients are extubated early after surgery comprising drainage of an intracranial hematoma. The present study also assessed whether early extubation was associated with a reduced ICU stay.

\section{Materials and methods}

Patients. The present study was a controlled, experimental, cross-sectional, prospective, comparative, non-blinded clinical trial in post-surgery intracranial hematoma evacuation patients to assess fast track (early extubation) vs. conventional extubation in the period from January 2014 to August 2015 at the Hospital Universitario 'Dr Jose Eleuterio Gonzalez' (Monterrey, Mexico). The 17 patients included were randomly divided into two groups: In Group 1, patients were extubated at the end of the surgical procedure and in Group 2, the patients were extubated in a conventional manner $(8 \mathrm{~h}$ after the surgery was completed). In the randomization process, sealed envelopes with randomized computer results were used to assign each patient to one of the two groups. Patients about to receive open cranial surgery due to an intracranial hematoma with an anesthesia risk of I-III according to the American Society of Anesthesiologists (ASA) (9), an age of at least 18 years, no intubation prior to entering the operating room and a Glasgow score of $\geq 8$ were included (10).

Patients aged $<18$ years, those with catecholamine-secreting tumors, coagulation disorders, or decompensated heart or lung disease were excluded. Patients with a scheduled surgery in another area of the body and with hypovolemic shock were also excluded. Furthermore, patients whose surgeries lasted for $>480 \mathrm{~min}$ or were accompanied by massive or uncontrollable bleeding (loss of $50 \%$ of blood volume for $3 \mathrm{~h}(\sim 1 \mathrm{l} / \mathrm{h})$ or $>150 \mathrm{ml} / \mathrm{kg}$ of body weight or $>1.5 \mathrm{ml} / \mathrm{kg} / \mathrm{min}$ for $>20 \mathrm{~min}$ ) were eliminated.

Post-surgical procedures. The patients from the two groups were assessed on admission to the operating room according to established standards, and once the selection criteria were met, general anesthesia was induced with propofol $(2 \mathrm{mg} / \mathrm{kg})$ and fentanyl $(2 \mu \mathrm{g} / \mathrm{kg})$. Propofol administration was maintained as a continuous intravenous infusion. A dose of fentanyl of $1 \mu \mathrm{g} / \mathrm{kg} / \mathrm{h}$ was used for maintenance. The propofol infusion and fentanyl doses were adjusted based on hemodynamic parameters (blood pressure and heart rate). The main aim of the procedure was to reduce the time of extubation. Hemodynamic stability was also assessed post-operatively (number of anesthetic adjustments required to maintain hemodynamic parameters within $20 \%$ of pre-induction values).

The patient was extubated when the following criteria were fulfilled (11): Regular breathing, without intercostal retraction and with a respiratory rate of $>8$ breaths per minute, a telespiratory $\mathrm{CO}_{2}$ pressure of $<45 \mathrm{mmHg}$, an oxygen saturation $\left(\mathrm{SatO}_{2}\right)$ of $>95 \%$ with an inspired oxygen fraction of $100 \%$, presence of a swallowing reflex, body temperature between 36 and $37^{\circ} \mathrm{C}$, hemodynamic stability (a change in baseline blood pressure of $\leq 15 \mathrm{mmHg}$ ), and a cooperative and oriented patient able to respond to verbal orders.

Attempted fast-track extubation was performed after post-operative neurological assessment by the same responsible surgeon. The difference between the two groups was in extubation time criteria; extubation was $8 \mathrm{~h}$ after surgery in the conventional group, but extubation was immediately post-surgical in the fast-track group. If a patient did not meet the criteria, they were considered to have failed extubation and were transferred to the ICU to receive mechanical ventilation. Subsequently, they were declared as 'fast-track group patients with failed extubation'; no patients had that declaration.

Statistical analysis. Demographic variables are presented as $\mathrm{n}$ or mean \pm standard deviation and described in Table I. Differences in the distribution of patients depending on their ASA score were analyzed using the chi-square test. For parameters described by continuous variables, a Kolmogorov-Smirnov test of normality was performed and 
Table I. Demographic data and ASA score in the two groups.

\begin{tabular}{lccc}
\hline & $\begin{array}{c}\text { Group 1: } \\
\text { Early extubation } \\
\text { (fast track) } \\
(\mathrm{n}=10)\end{array}$ & $\begin{array}{c}\text { Group 2: } \\
\text { Conventional } \\
\text { extubation } \\
(\mathrm{n}=7)\end{array}$ & \\
Parameters & & & P-value \\
\hline Sex & 8 & 7 & 0.99 \\
Male (n) & 2 & 0 & \\
Female (n) & $50.50 \pm 21.15$ & $48.28 \pm 19.42$ & 0.87 \\
Age (years) & $66.60 \pm 7.24$ & $72.57 \pm 5.98$ & 0.82 \\
Weight (kg) & $164.6 \pm 11.39$ & $168.57 \pm 12.04$ & 0.91 \\
Height (cm) & & & 0.34 \\
ASA score & 4 & 1 & \\
I & 5 & 4 & \\
II & 1 & 2 & \\
III & 0 & 0 & \\
IV & 0 & 0 & \\
V & & &
\end{tabular}

Age, weight and height are presented as mean \pm standard deviation. ASA, American Society of Anesthesiologists.

differences between groups were determined using Student's t-test or a Mann-Whitney U-test as appropriate. SPSS version 21 software (IBM Corp.) was used for statistical analysis.

For comparison of parameters throughout the post-operative period, including blood pressure, heart rate, respiratory rate, $\mathrm{SatO}_{2}$ or Glasgow coma scale score, a general linear model was used to determine the differences between repeated measurements. Comparisons with a p-value of $\leq 0.05$ were significant; all the hypothesis tests were two-tailed.

\section{Results}

Patient characteristics. The data from the 17 patients were analyzed; 7 patients were subjected to conventional extubation and 10 to fast-track extubation after surgery. There was no statistically significant difference in age, weight, height and ASA scores between groups (Table I).

Post-surgical condition and extubation. The respiratory rate was regular throughout the patient follow-up. Only one patient in the fast-track group had an irregular respiratory rhythm at the beginning of the study, due to the use of accessory muscles. During the post-operative observation, no significant differences in post-operative blood pressure changes were observed between the two groups; a peak in blood pressure was observed at $30 \mathrm{~min}$ post-extubation for the fast-track group and at $4 \mathrm{~h}$ for the conventional treatment group. These observations may correspond to the time sequence of extubation attempts (Fig. 1A). In regards to the heart rate (HR), no significant difference was observed between the two groups at all time points $(\mathrm{P}=0.58)$; however, those patients with conventional management had a tendency of low heart rates during most of the follow-up; the conventional group had a decrease in $\mathrm{HR}$, but it was reestablished at next measurement $(4 \mathrm{~h}$ post extubation). This may be due to the persistent use of sedation and longer times under mechanical ventilation (Fig. 1B). For the respiratory rate, the statistical difference between the two groups was observed to be not significant except for $0.5 \mathrm{~h}$ after the procedure $(\mathrm{P}=0.021)$ (Fig. 1C). The patients in the fast-track group had a higher respiratory rate, and the fast-track treatment appears to be the cause of this difference (Fig. 1C). Also, no significant differences in $\mathrm{SatO}_{2} \%$ measurements were identified between the groups ( $\mathrm{P}=0.63$; Fig. 1D). Blood $\mathrm{pH}$ values were not significantly different between the two groups (Fig. 1E). The Glasgow Come Scale score was significantly different fast-track against conventional extubation $(\mathrm{P}=0.001$; Fig. $1 \mathrm{~F})$. Only three of the 17 patients evaluated were extubated after the first $8 \mathrm{~h}$.

Complications. Among the patients who were extubated in a conventional manner ( $\geq 8 \mathrm{~h}$ after the end of surgery), one presented with a seizure and was re-intubated and transferred to the ICU; one presented with signs of aspiration and was not able to remain extubated for a long time. None of the patients who had the fast track procedure presented with complications and all were neurologically assessed at the end of the surgery. However, certain clinical complications were observed in the conventional extubation group when compared with the fast track group, including a torpid outcome in four of the seven patients evaluated, seizure in one patient and failed extubation in three cases with development of pulmonary atelectasis $(n=2)$ and aspiration $(n=1)$. A total of four patients were classified as cases of failed extubation due to pulmonary complications. Compared with the fast track group, significant differences in clinical complications events were observed in the conventional extubation group (57\%; $\mathrm{P}=0.015$; data not shown).

There was no significant difference in the procedure depending on age $(\mathrm{P}=0.87)$, sex $(\mathrm{P}=0.99)$ or surgical risk ASA score $(\mathrm{P}=0.35)$ among patients with complications or those with a favorable outcome (Table II). The relative risk of the fast track procedure compared with conventional extubation was determined as 0.2727 (95\% CI, 0.0126-5.9166), which was not significant $(\mathrm{P}=0.4079)$. Differences in extubation time between the two groups were $40 \pm 20 \mathrm{~min}$ for the fast-track group, whilst for conventional patients they were $940 \pm 480 \mathrm{~min}$ (Fig. 2).

\section{Discussion}

The results of the present study indicate that patients who remain intubated and undergo mechanical ventilation at the ICU present with more complications than those who are extubated early if they meet the necessary criteria. Cai et al (12) assessed the causes of delayed extubation of neurosurgical patients. That study included 800 patients subjected to craniotomy for resection of intracerebral tumors, of which 398 (49.8\%) received delayed extubation. Bruder and Ravussin (8) provided information regarding the factors associated with this delay were dysfunction of the cranial nerves, hydrocephalus, tumor location, duration of surgery of $>6 \mathrm{~h}$ and blood loss of $>1,000 \mathrm{ml}$. In a previous clinical study conducted by Bruder and Ravussin (8), patients exhibited greater severity of pneumonia, a prolonged stay at the ICU and at the hospital with higher hospitalization costs compared with the early extubation group in the present study. 

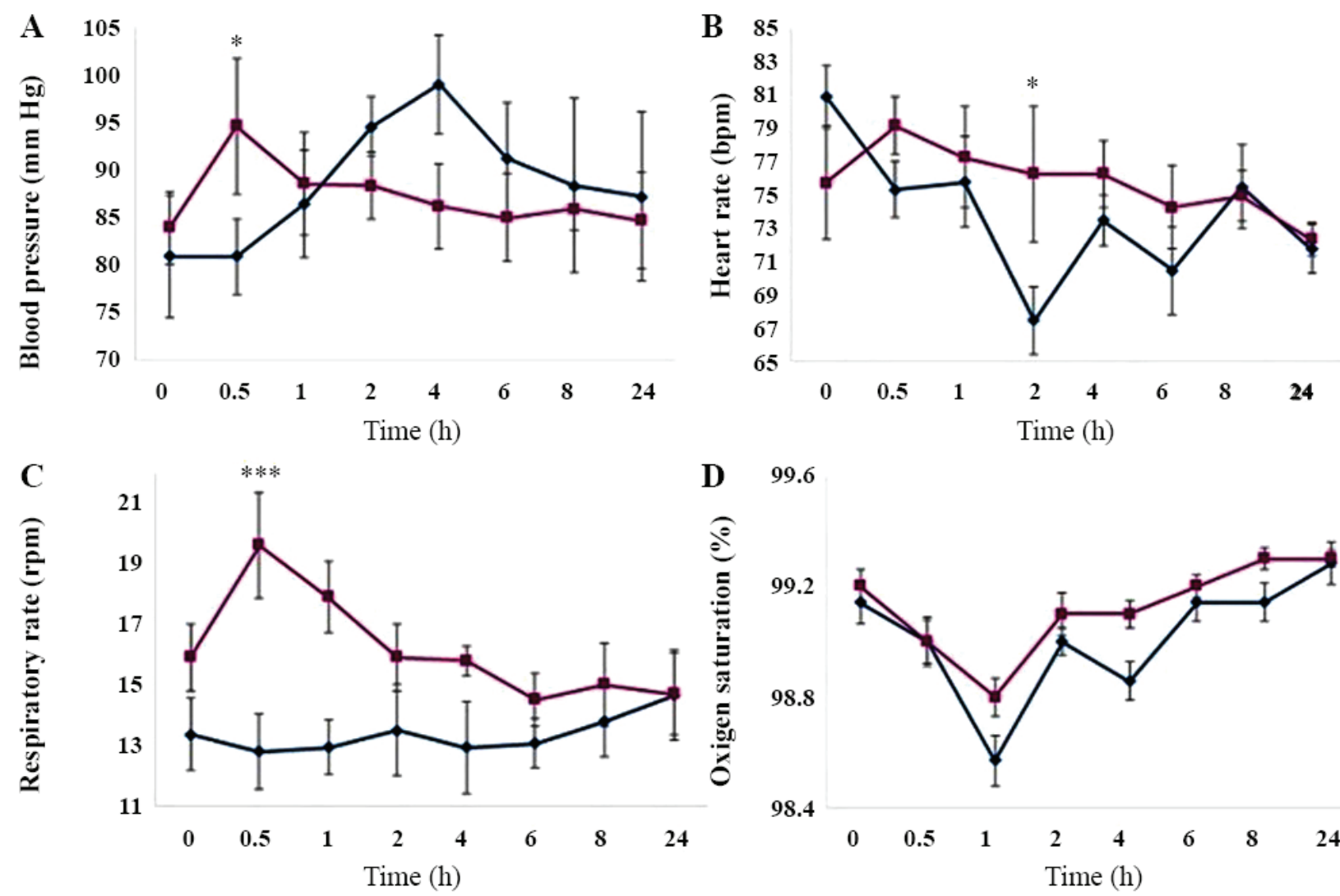

D 99.6
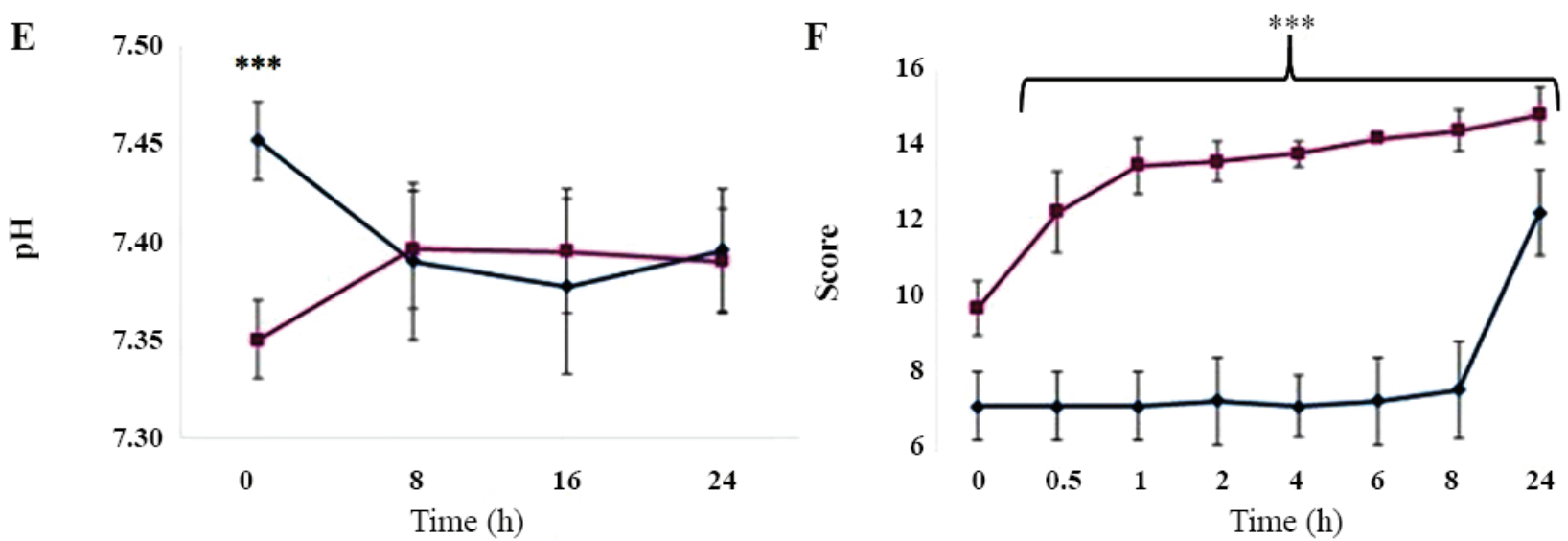

\footnotetext{
$\rightarrow$ Conventional

Fast track
}

Figure 1. Post-operative changes in clinicopathological parameters in the two different groups. (A) Mean arterial blood pressure. (B) Heart rate. (C) Respiratory rate. (D) Arterial $\mathrm{O}_{2}$ saturation. (E) Arterial blood pH. (F) Glasgow coma scale score. rpm, respirations per minute; bpm, beats per minutes. " $\mathrm{P}<0.05$ and ${ }^{* * * *} \mathrm{P}<0.001$ vs. Conventional.

Cai et al (12) determined predictive factors of extubation failure in 2,118 patients who underwent craniotomy; in this cohort, the extubation attempt failed in 94 patients (4.4\%). A number of major factors were identified to be predictors of extubation failure: Previous craniotomy, cranial nerve dysfunction, tumor size, tumor site and extreme changes in blood pressure during surgery. Failed extubation was also associated with pneumonia, ICU mortality, unfavorable Glasgow scale score, longer ICU and hospital stay, and higher hospital costs compared to patients who were successfully extubated (12). In the present study, patients who were extubated later than those who were extubated early also had complications including seizures, failed extubation, atelectasis and aspiration.

If the patient is suitable for early extubation, this should be attempted to avoid the use of mechanical ventilation at the ICU, since this is a pre-disposing factor for respiratory complications, hospital infections, neuroinfection and death. In a study by Vora et al (13) on 1,150 patients who were intubated prior to admission to the ICU, the survival rate was $57.75 \%$, with ventilator-associated pneumonia being the most common complication (53.33\%), followed by decubitus ulcers (40\%) and deep venous thrombosis (8.89\%). The cost of ventilator-associated complications is high; therefore, patient 
Table II. Vital signs $0.5 \mathrm{~h}$ after extubation procedure.

\begin{tabular}{|c|c|c|c|}
\hline Parameter & $\begin{array}{c}\text { Group 1: } \\
\text { Early extubation (fast track) } \\
(\mathrm{n}=10)\end{array}$ & $\begin{array}{c}\text { Group 2: } \\
\text { Conventional extubation } \\
(\mathrm{n}=7)\end{array}$ & P-value \\
\hline MAP (mean) mmHg & $94.500 \pm 17.190$ & $80.850 \pm 11.890$ & 0.033 \\
\hline $\mathrm{SatO}_{2}(\%)$ & $99.000 \pm 0.940$ & $99.000 \pm 0.580$ & 0.500 \\
\hline Body temperature $\left({ }^{\circ} \mathrm{C}\right)$ & $36.800 \pm 0.010$ & $36.590 \pm 0.230$ & 0.099 \\
\hline Heart rate (beats/min) & $79.100 \pm 15.750$ & $75.290 \pm 10.950$ & 0.277 \\
\hline Respiratory rate (breaths/min) & $19.000 \pm 4.180$ & $12.430 \pm 1.610$ & 0.003 \\
\hline
\end{tabular}

MAP, mean arterial pressure; $\mathrm{SatO}_{2}$, arterial oxygen saturation.

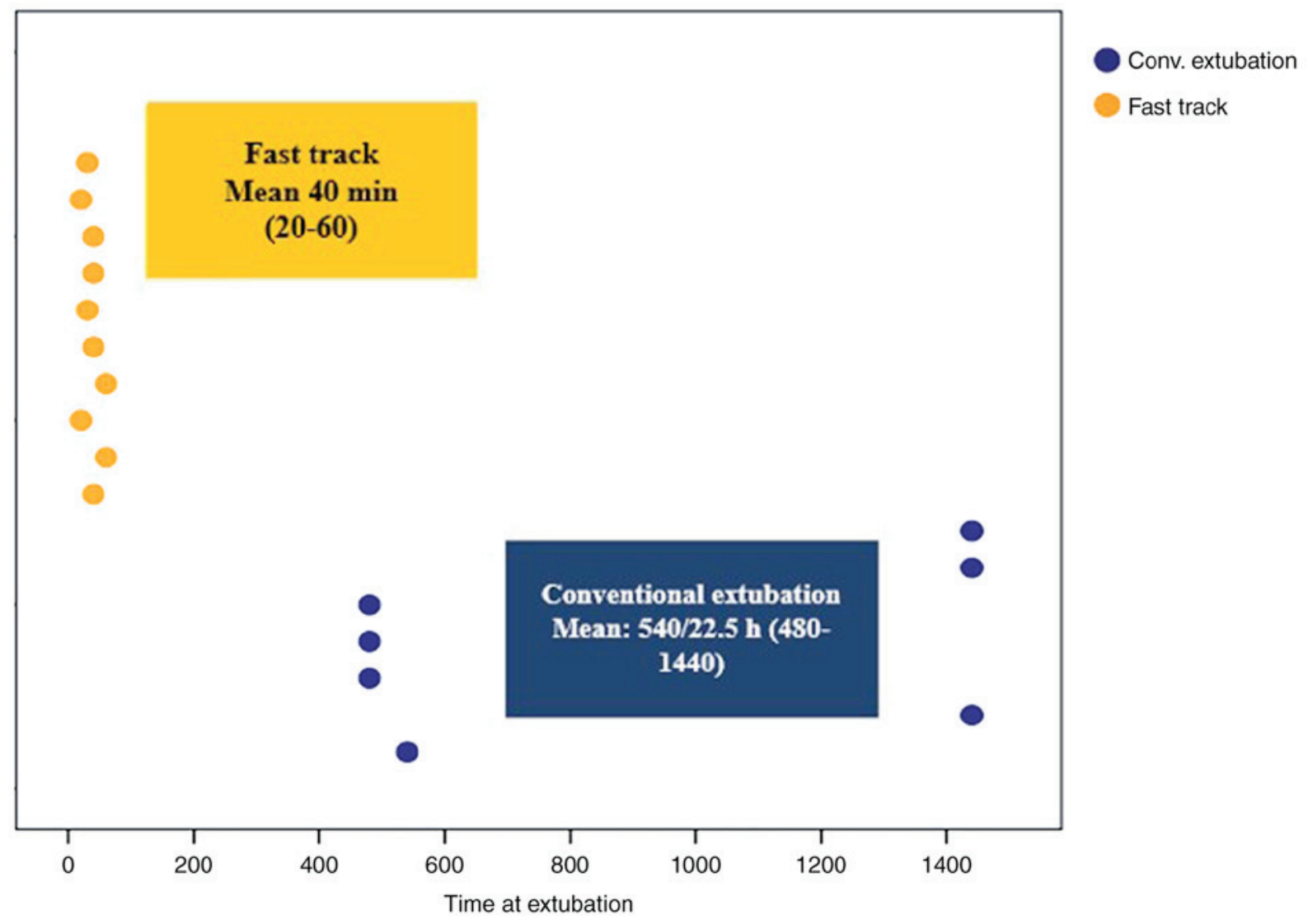

Figure 2. Comparison of extubation time (min) among patients in the two groups.

intubation for an extended period should be avoided as much as possible (13).

Another study indicated that ventilator-associated pneumonia ( $S$. aureus or $P$. aeruginosa) contributed to patients remaining intubated for 37.9 days (S. aureus) or 55.4 days (P. aeruginosa) on average, while non-intubated patients had decreased average duration of hospitalization of 7.2 days; in addition, the ICU stay for those intubated patients was longer (6.9 or 14.8 vs. 1.1 days), mechanical ventilation use was increased (62.6 or 62.3 vs. $7.4 \%$ ), the mortality rate was higher (16 or 20.2 vs. $3.1 \%$ ) and the mean cost of hospitalization was higher (US\$ 146,978 or 213,104 vs. 33,851$)(13)$. The study also indicated that pneumonia survivors had an increased risk of re-hospitalization at 30 days (27.2 or 31.1 vs. $15.3 \%$ ) and it was concluded that the cost, staffing levels and material resources used in health care were higher in ICU patients with ventilator-associated pneumonia ( $S$. aureus or $P$. aeruginosa). By reducing the incidence of hospitalizations in those ICU of patients who may be extubated in the operating room, the rate of ventilator-associated pneumonia, hospital morbidity and mortality, as well as hospitalization cost are accordingly reduced (14).

Early self-awakening of a neurosurgical patient is, in most cases, a surgeon's request, since obeying orders and responding to verbal commands indicate, to a certain point, neurological stability. Namen et al (15) reported a marked increase in 
successful extubation in neurosurgical patients with a Glasgow coma score $>8$. They identified extubation failure in $61 \%$ of patients with a Glasgow coma score of $\leq 8$ (15). The present study was based on these results and extubation was attempted only in patients who entered the operating room without intubation and with a Glasgow score of $\geq 8$.

The intention of the present study was to reduce, as much as possible, the ICU stay of patients and the time on mechanical ventilation, and the present results confirm what previous studies reported $(11,12,15)$. In the present study, it was possible to create a similar setting in the two groups of patients regarding hemodynamics, respiratory rate, temperature, $\mathrm{SatO}_{2}$, expired $\mathrm{CO}_{2}$ stability and acid-base balance throughout the surgical event and up to $24 \mathrm{~h}$ later. Therefore, the statistical analysis does not indicate any significant difference between the groups. This stability allows for comparison of patients subjected to extubation at an early stage and those intubated for $>8 \mathrm{~h}$ after the surgical procedure. The present study provides a clear indication that the use of mechanical ventilation may be a factor that complicates the respiratory status of these patients, leading to even more serious conditions, including hypostatic pneumonia or contamination of mechanical ventilators; in addition, due to the presence of antibiotic-resistant bacteria at the ICU, those patients are at risk of neuroinfection, a condition with severe adverse outcomes. This indicates that complications associated with ventilator use in intensive care may be reduced if the patient meets the criteria necessary for extubation, in both conventional and fast track procedures.

For the surgeon, flexibility is required regarding the previously made decisions that are intended to benefit the patient. However, a neurosurgeon under pressure should be cautious not to make any hasty decisions. Hypothermia, pre-existing neurological damage or damage generated during surgery remain key points to consider when selecting the time-point of awakening and extubation for a patient. Finally, it should be remembered that the protocol for early extubation is not rigid and the fast-track strategy may be discarded immediately if the patient's condition is not ideal. With the purpose of standardizing the technique of early extubation in the management of the neurosurgical patient, rigorous controlled trials should be performed in the future to further evaluate techniques.

Fast track should be regarded as a routine technique in patients who meet the required criteria, so that they may be discharged faster and with fewer complications that may potentially endanger their lives or prolong their hospital stay. Deliberate delay or failed extubation increases the incidence of post-operative pneumonia, mortality and longer stays in the ICU and hospital. Another important issue, after considering the patient's life and safety first, is the economic factor. If the patient is discharged without admission to the ICU, the economic burden for the patient, the hospital or the medical insurance company is significantly reduced.

\section{Acknowledgements}

Not applicable

\section{Funding}

No funding was received.

\section{Availability of data and materials}

The datasets used and/or analyzed during the present study are available from the corresponding author on reasonable request.

\section{Authors' contributions}

GGC designed the experiments, performed experiments, analyzed data and co-wrote the paper. YNES and BIGC performed the experiments. DPR designed the experiments and co-wrote the paper. IPRS, designed part of trial and co-wrote the manuscript. ARMPDL analyzed data and co-wrote the paper.

\section{Ethical approval and consent to participate}

The present study was authorized by the ethics committee of Hospital Universitario 'Dr Jose Eleuterio Gonzalez' (Monterrey, Mexico) and the research sub-directorate with the number AN14-003. Patients provided informed consent.

\section{Patient consent for publication}

Not applicable.

\section{Competing interests}

The authors declare that they have no competing interests.

\section{References}

1. Myles PS, Daly DJ, Djaiani G, Lee A and Cheng DC: A systematic review of the safety and effectiveness of fast-track cardiac anesthesia. Anesthesiology 99: 982-987, 2003.

2. Henao FA, Restrepo CE, Botero LF, Arango MF and Jaramillo AF Extubación temprana (fast-track) en neuroanestesia: Una alternativa segura? Rev Col Anest 32: 179-184, 2004.

3. González-Villavelázquez ML, Castelazo-Arredondo JA and Osorio-Santiago MA: Extubación temprana en neurocirugía. Revista Mexicana de Anestesiología. Neuroanestesiología 28 (Suppl 1): S120-S112, 2005.

4. Souter MJ and Manno EM: Ventilatory management and extubation. Criteria of the Neurological/Neurosurgical patient. Neurohospitalist 3: 39-45, 2013.

5. Mayer SA, Copeland D, Bernardini GL, Boden-Albala B, Lennihan L, Kossoff S and Sacco RL: Cost and outcome of mechanical ventilation for life threatening stroke. Stroke 31: 2346-2353, 2000.

6. Gujjar AR, Deibert E, Manno EM, Duff S and Diringer MN: Mechanical ventilation for ischemic stroke and intracerebral hemorrhage: Indications, timing, and outcome. Neurology 51: 447-451, 1998.

7. Cooper RN: Desintubación segura. In: Clínicas anestesiológicas de Norte América, Editorial Ciudad de Mexico, Interamericana Mc Graw Hill, pp680-706, 1995.

8. Bruder $\mathrm{N}$ and Ravussin P: Recovery from anesthesia and postoperative extubation of neurosurgical patients: A review. J Neurosurg Anesthesiol 11: 282-293, 1999.

9. Borstnar CR and Cardellach F: Farreras Rozman. Medicina Interna. Elsevier Health Sciences, 2016. American Society of Anesthesiologist. New Classification of Physical Status. Anesthesiology 24: 111, 1963.

10. Spahn DR and Rossaint R: Coagulopathy and blood components transfusion in trauma. Br J Anaesthes 95: 130-139, 2005.

11. Cai YH, Zeng HY, Shi ZH, Shen J, Lei YN, Chen BY and Zhou JX: Factors influencing delayed extubation after infratentorial craniotomy for tumour resection: A prospective cohort study of 800 patients in a Chinese neurosurgical centre. J Int Med Res 41: 208-217, 2013. 
12. Cai YH, Wang HT and Zhou JX: Perioperative predictors of extubation failure and the effect on clinical outcome after infratentorial craniotomy. Med Sci Monit 22: 2431-2438, 2016.

13. Vora CS, Karnik ND, Gupta V, Nadkar MY and Shetye JV: Clinical profile of patients requiring prolonged mechanical ventilation and their outcome in a tertiary care medical ICU. J Assoc Physicians India 63: 14-19, 2015.

14. Kyaw MH, Kern DM, Zhou S, Tunceli O, Jafri HS and Falloon J: Healthcare utilization and costs associated with $S$. aureus and $P$. aeruginosa pneumonia in the intensive care unit: A retrospective observational cohort study in a US claims database. BMC Health Serv Res 15: 241, 2015.
15. Namen AM, Ely EW, Tatter SB, Case LD, Lucia MA, Smith A, Landry S, Wilson JA, Glazier SS, Branch CL, et al: Predictors of successful extubation in neurosurgical patients. Am J Respir Crit Care Med 163: 658-664, 2001.

This work is licensed under a Creative Commons Attribution-NonCommercial-NoDerivatives 4.0 International (CC BY-NC-ND 4.0) License. 